\title{
Comparison of Obstetric Care in Germany and in the Netherlands
}

\author{
Birgit Arabin ${ }^{1,3 *}$ and Gerard HA Visser ${ }^{2,3}$ \\ ${ }^{1}$ Centre for Mother and Child of the Philipps University Marburg, Baldingerstr 1, 35033, Marburg, Germany \\ ${ }^{2}$ Department Obstetrics, University Medical Center, Utrecht, the Netherlands
}

${ }^{3}$ Clara Angela Foundation Witten, Germany

\begin{abstract}
Germany and the Netherlands are wealthy countries in close neighborhood within Europe. They both have a general health care insurance system and a tradition of recognized research in perinatal medicine. Nevertheless, there are significant differences in the way how obstetric training and care are organized: Germany had two different health care systems (East/West) from 1945 to 1990, in the Netherlands, home deliveries are still common. Today, the number of gynecologists per patient is much higher in Germany compared to the Netherlands. In Germany, training of residents is still not supervised whereas in the Netherlands there is a long tradition of audits of the training facilities. Amazingly, in Germany there is no established guideline group of the professional boards whereas in the Netherlands, all guidelines are democratically established, recognized by the boards and made transparent to patients and physicians. The scientific output in high-impact journals is much higher in the Netherlands compared to Germany. Lessons to learn are to adapt the number and quality of our future obstetricians including participation in research lines and interpretation of the literature. There is a need for a standardized audit and accreditation system for training in Germany. This also implies the establishment of competent guidelines, standards and confidential inquiries not only for pre- and postgraduate training but also for transparency towards the patients.
\end{abstract}

Given the differences between both countries we hopefully can learn from each other to improve future care of the fetal and maternal patient and thereby neglect harmful sides and introduce useful aspects.

\section{Introduction}

Obstetrics in Germany and in the Netherlands does not differ much from that of other Western countries, in terms of medical knowledge and equipment of perinatal surveillance with relatively low maternal and perinatal mortality rates compared to worldwide statistics. Both countries are in close neighborhood, have a comparable high standard of living; a similar population and both have large immigrant populations.

Nevertheless, within Europe, maternal and perinatal mortality (mainly before 28 weeks) are relatively high in the Netherlands compared to Germany and lowest in Scandinavian countries [1-5] whereas total prematurity rate is lower in the Netherlands than in Germany [6].

Besides in outcome parameters, there are other differences, like in the care of low-risk women, academic training of obstetricians, international scientific output, guidelines and organizational structures. This is why the authors thought it would be worthwhile to compare the obstetric care in both countries. The most interesting aspects are, ...

- That Germany had two completely different health care systems within the former East and West Germany from 1945 until 1990.

- That the Netherlands is the only country in the Western world where home deliveries are still rather common although they have been continuously decreasing to meanwhile around one fourth of all deliveries.

In addition, there are other differences which could be of interest for future learning namely...

- That the number of gynecologists per patient is much higher in Germany (around 40,000 registered) compared to the Netherlands (around 1000 registered). Thereby more than 50\% of German gynecologists have a private practice, seeing patients only on an outpatient basis, whereas in the Netherlands both outpatient and clinical obstetric care of risk pregnancies take place at hospitals.

- That in the Netherlands training of residents is supervised by an obligatory audit system, while in Germany the training of residents is not supervised.

- That in the Netherlands there is a continuous working group for obstetric guidelines which does not exist in Germany.

- That in spite of the difference in the number of specialists the scientific output in international journals is much higher in the Netherlands, whereby during the last years the Dutch Consortium (network for studies) comprising the efforts of many Dutch academic and non-academic centers has largely contributed to this success.

In this review mainly the first two unique aspects will be illustrated, whereby all aspects will be discussed to address strengths and weaknesses of both obstetric health care systems (Table 2) and thus to learn our lessons. Thereby former and recent papers are referred to and some text is largely taken from reviews of both authors $[7,8]$.

The origin of obstetric care in East and West Germany (Berlin) from 1945 to 1990 before the reunification but within the time of the introduction of prenatal and perinatal care.

\section{Development of different perinatal care with a common history of health care}

Germany has had a distinguished tradition of social welfare. Basic

${ }^{*}$ Corresponding author: Birgit Arabin, Centre for Mother and Child of the Philipps University Marburg, Baldingerstr 1, 35033, Marburg, Germany, Tel: +4915150479484; Fax: +49721509663784; E-mail: bine.clara.angela@gmail.com

Received May 28, 2013; Accepted June 25, 2013; Published June 29, 2013

Citation: Arabin B, Visser GHA (2013) Comparison of Obstetric Care in Germany and in the Netherlands. J Health Med Informat S11: 014. doi:10.4172/2157-7420. S11-014

Copyright: (C) 2013 Arabin B, et al. This is an open-access article distributed under the terms of the Creative Commons Attribution License, which permits unrestricted use, distribution, and reproduction in any medium, provided the original author and source are credited. 
reforms including a law on health care were introduced in 1883 . The social security health care system was reformed in 1910, and it survived two world wars. Having roots in the same tradition, East and West German health care systems diverged after World War II.

East Germany switched towards a national socialist, state financed health system, with the possibility to voluntarily purchase private health insurance for additional treatment. The most distinctive feature of this system was the introduction of centralized state control, including ambulatory care and basic physicians for family care at reasonable costs. Moreover, the East German government tried to influence family policy to an enormous extent from the 1970s onward, in that each family received financial support, inexpensive lodging, a one-year maternity leave after the delivery of a child (with a guaranteed job at the end of the period), and the establishment of kindergartens at workplaces. This latter entitlement facilitated the life of young mothers and led not only to an increase of pregnancies in East Germany, but also to the possibilities to become pregnant of the first child already at an increasing young age compared to mothers in West Germany (Figure 1).

In contrast, the system in West Germany expanded health care coverage by an obligatory insurance system developing into a highly decentralized corporate system developed in the face of modest parliamentary control. More than 1000 autonomous sickness funds arose, which led to a broad coverage within the free market. Prior to unification, this system covered about $90 \%$ of the population, with the remaining $10 \%$ purchasing private insurance. Ambulatory care was and still is provided mainly by private specialists.

In the 1960s, pre- and postnatal care became an essential part of preventive health care in the Western world. At the same time, maternal foetal medicine developed to a new and previously unimagined level. One of the pioneers of perinatal medicine, Erich Saling whose personal energy attracted clinicians and researchers to his conferences in Berlin introduced as one of others new diagnostic concepts and therapeutic methods in which the foetus was increasingly recognized as a potential patient [9].

The division of Germany and Berlin created deep cultural strain for all citizens. Different political and economic systems had an impact on women who were originally homogeneous across tradition, education, ethnicity, and cultural identity. The reunification of Germany facilitated access on data base systems and thus to compare the increasing impact of different political system and economics on health care and mainly on perinatal care in both parts of Germany and most interestingly, of

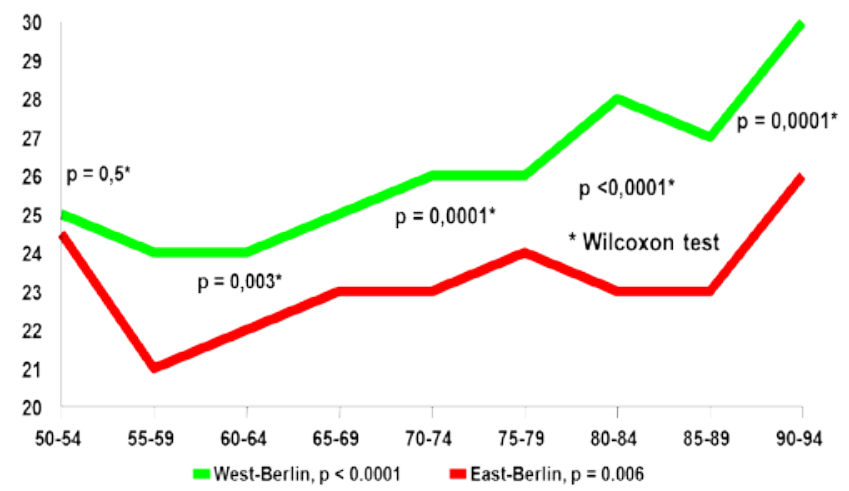

Figure 1: Maternal age at the delivery of the first child within the time of two different health care systems in East and West Berlin. the former West and East Berlin and thus to compare various aspects of perinatal care.

\section{Introduction of pre and perinatal interventions in the former East and West Berlin}

During the described interval we investigated the differences of the introduction of different screening methods, organization of care and transfer as well as diagnostic/therapeutic measures. Table 1 indicates the year when a specific method or protocol was introduced in one hospital for the first time and when it became a routine clinical procedure covering all patients. Included were sophisticated techniques as ultrasound and fetal heart monitoring, which were introduced early in West Berlin (and West Germany) the routine use of Pharmaceuticals (e.g., oxytocin, prostaglandins, and peridural anesthesia). For example, the mean year when peridural anesthesia was used routinely in West Berlin was 1972 compared with 1987 in East Berlin. In contrast, certain important public health measures, such as prenatal classes, screening for diabetes during pregnancy, and the prenatal transport of mothers with high-risk pregnancies to a center with neonatal intensive care, were introduced much earlier in East Berlin than in West Berlin. For example, maternal transfer became routine in East Berlin in 1970 as compared with 1987 in the West. The Data show striking differences in the early access to technological innovations or pharmaceutical agents on one side but also the use of more basic measures of maternal care between East and West.

Contemplating these differences, it is important to remember that, high-technology medicine mainly improves the survival of patients who already suffer from a disease. In contrast, introducing benefits during pregnancy and the first year of life or a policy supporting women to become pregnant when they are young as well as the general use of screening procedures, reduces the relative need for high technology during pregnancy and delivery. Therefore the outcomes within both parts were surprisingly not significantly different although the costs for care were much less in East Germany.

\section{Perinatal outcome in Berlin during 1950 and 1990}

As in all Western countries maternal mortality per 1000 live births decreased continuously in both parts of the city between 1950 and 1990, from 1.76/1000 (West) and 1.9/1000 (East) to 0.04/1000 (West) and $0.06 / 1000$ (East), respectively. Similarly, the infant mortality decreased from 56.7/1000 (West) and 76.8/1000 (East) in 1950 to 9.1/1000 (West) and 6.9/1000 (East) in 1990. To compare: In the same year, namely 1990, infant mortality was 7.1/1000 for all of Germany and 9.1/1000 for the U.S [10]. The differences in both maternal and infant mortality between the two parts of Berlin were not significant.

Perinatal mortality (mortality during delivery and mortality up to seven days post-partum of children with birth weights $>1000 \mathrm{~g}$ ) could only be obtained from 1970 onward because varying definitions of mortality used before that time. Similarly, data on prematurity prior to 37 completed weeks could only be evaluated from 1970 onward.

As in other industrialized countries, perinatal mortality decreased between 1970 and 1990 in both parts of Berlin without significant differences between East and West Berlin.

Similarly, preterm delivery rates ( $<37$ weeks) decreased in both parts of the city between 1970 and 1990 with slightly lower rates in East Berlin.

\section{Development of the system after 1990}

From 1990 to 1994, the number of deliveries in West and East 
Citation: Arabin B, Visser GHA (2013) Comparison of Obstetric Care in Germany and in the Netherlands. J Health Med Informat S11: 014. doi:10.4172/2157-7420.S11-014

Page 3 of 8

\begin{tabular}{|c|c|c|c|c|}
\hline Procedure & $\begin{array}{l}\text { First application } \\
\text { West Berlin }\end{array}$ & $\begin{array}{l}\text { First application } \\
\text { East Berlin }\end{array}$ & $\begin{array}{l}\text { Routine application } \\
\text { West Berlin }\end{array}$ & $\begin{array}{l}\text { Routine application } \\
\text { East Berlin }\end{array}$ \\
\hline Screening preeclampsia & 1953 (1951-1955) & $1953(1951-1955)$ & 1954 (1952-1957) & 1954 (1953-1957) \\
\hline Screening gestational diabetes & 1968 (1963-1971) & $1955(1953-1957)^{\mathrm{b}}$ & $1971(1966-1971)$ & $1957(1954-1958)^{b}$ \\
\hline Antenatal classes & 1964 (1955-1965) & $1956(1954-1957)^{a}$ & 1967 (1958-1968) & $1956(1954-1957)^{b}$ \\
\hline Promotion breastfeeding & $1966(1965-1973)$ & $1956(1954-1964)^{b}$ & 1967 (1966-1973) & $1962(1957-1964)^{b}$ \\
\hline Rh prophylaxis & 1967 (1966-1968) & 1967 (1966-1970) & 1967 (1966-1972) & 1967 (1966-1972) \\
\hline Intrauterine transfer & 1987 (1986-1987) & $1970(1970-1972)^{a}$ & 1987 (1986-1988) & $1970(1970-1973)^{b}$ \\
\hline Primary neonatal care & 1967 (1966-1972) & 1967 (1967-1970) & 1968 (1966-1972) & 1968 (1968-1970) \\
\hline Apgar/ pH umbilical artery & $1963(1960-1966)^{a}$ & 1969 (1967-1969) & 1966 (1960-1966) & 1968 (1966-1968) \\
\hline Amnioscopy & $1960(1960-1961)$ & $1962(1962-1964)$ & $1962(1960-1963)$ & 1965 (1962-1967) \\
\hline Fetal blood sampling & $1964(1962-1967)^{a}$ & $1970(1967-1972)$ & $1967(1962-1967)^{a}$ & $1972(1971-1976)$ \\
\hline FHR monitoring & $1966(1966-1966)$ & $1970(1968-1971)$ & $1967(1966-1968)^{a}$ & 1973 (1972-1977) \\
\hline Amniocentesis/prenatal diagnosis & $1955(1954-1961)^{b}$ & $1973(1972-1976)$ & $1973(1972-1973)$ & $1977(1973-1982)$ \\
\hline Ultrasound & $1967(1966-1970)^{a}$ & $1975(1970-1977)$ & $1972(1967-1972)^{a}$ & 1977 (1973-1978) \\
\hline Lung maturity testing & $1972(1971-1973)$ & 1973(1972-1975) & 1976 (1971-1983) & $1976(1973-1978)$ \\
\hline Doppler & 1984 (1982-1987) & 1987 (1986-1988) & 1986 (1986-1987) & 1988 (1986-1989) \\
\hline Tocolytic treatment & 1967 (1967-1969) & 1967 (1967-1969) & $1971(1967-1973)$ & $1973(1972-1974)$ \\
\hline Induction lung maturity & $1973(1973-1974)$ & $1976(1975-1976)$ & 1975 (1972-1978) & 1976 (1976-1977) \\
\hline Cervical ripening & $1976(1976-1977)^{a}$ & $1982(1977-1984)$ & $1977(1976-1981)^{a}$ & 1986 (1986-1987) \\
\hline Oxytocin during labor & $1963(1962-1967)$ & $1963(1960-1965)$ & $1967(1963-1969)^{a}$ & $1976(1964-1966)$ \\
\hline Peridural anesthesia & $1970(1967-1973)^{b}$ & $1980(1972-1987)$ & $1972(1971-1976)^{\mathrm{b}}$ & 1987 (1974-1987) \\
\hline
\end{tabular}

a: >Five years ahead. b: > Ten years ahead.

Table 1: Year of First and Routine Introduction of New Techniques or Policies for Maternal-Child Health Care in East and West Berlin between 1950 and 1990.

Germany decreased dramatically mainly due to the decrease within the new former Eastern provinces namely from 178000 to 79 000/year in the so-called "new Eastern provinces". Meanwhile, since 2000 deliveries in the new Eastern provinces again increased to around 100000/year, whereby the relative increase from 2007-2010 was with 3.5\% higher than in the former Western provinces with only $2.6 \%$. From all deliveries now only $15 \%$ are born in the so-called new provinces. Thereby now $81 \%$ of possibly fertile women live within the former West, $14 \%$ in the new provinces and 5\% in Berlin. Nevertheless, all this shows how sensitive women are why and when to plan or allow becoming pregnant.

The number of deliveries is not only dependent on the number of women at the age of 15-49 years, but mainly on the number of women with a high pregnancy rate since $60 \%$ of all newborns have mothers at the age of 26 to 35 years. This group decreased between 1990 and 2010 by 1.5 million women, whereby the percentage dropped from $33 \%$ to $25 \%$ among the whole group of $15-49$ years. This trend will probably continue.

Within the last 20 years, the age of women delivering the first child increased in the new provinces from 22.9 to 27.4 years. This increase is comparable to the increase in the former Western provinces between 1970 and 2010! Reasons could be the increasing freedom to travel and to develop but also insecurities of working conditions, the increasing lack of family support and a so-called "new orientation" within a global society.

Meanwhile, within the European comparison, Germany has one of the lowest rate of children per woman, namely 1.36 compared to the Netherlands with relatively high pregnancy and delivery rate of 1.79 per woman [11].

More than 20 years after the reunification, it is possible to look back upon recent health care systems developments that have taken place. Considering our results, it would have been wise to reflect upon the advantages of both health care systems and possibly find a constructive solution. Instead, the Western health care system was rapidly introduced in the East; even structures (e.g., policlinics with a defined referral system instead of single private-physicians' offices) that had been proven to be cost effective were eliminated. The main reason was not only the initial general political enthusiasm but also the fact that West German physicians were organized in interest groups with strong economic power. It is only now that these developments are more openly discussed last not least due to the increasing costs of the competitive behavior of many hospitals and specialists who previously had no economic interests. This could be demonstrated by increasing costs per patient (Figure 2 top) and per hospital (Figure 2 bottom).

Advances in medical science and technology undoubtedly will continue. However, the financial and personal resources may not keep pace with those changes. The cardinal principals of medical ethics are to protect life and health, to respect autonomy, and to strive for equality. This also holds true for maternal and child care. Emphasizing the right of individuals, as is so often done in Western health care systems, might be seen as a defense against the abuse of power found in totalitarian systems that in the past abused individuals in the name of society. Alternatively, the liberal health care systems may be linked to increasing prosperity, leaving out others with marginal incomes, thus creating inequality.

\section{Home deliveries in the Netherlands and its impact on perinatal outcome}

The persistence of home births during the introduction of sophisticated perinatal care: Home births were common in Europe until the mid-1950s. At that time, however, obstetricians generally became aware that deliveries at home were hazardous and less safe than those in hospital, where modern technology was increasingly available to safeguard the health of mother and infant during labor. In the Netherlands, on the other hand, the view prevailed that birthing is essentially a physiological event and that home delivery would prevent unnecessary obstetrical interventions, which might increase the risk to mother and fetus. In most of the European countries, politicians followed the advice of the obstetricians and within a span of five to ten years all home deliveries had disappeared, whereas in the Netherlands, 
Citation: Arabin B, Visser GHA (2013) Comparison of Obstetric Care in Germany and in the Netherlands. J Health Med Informat S11: 014. doi:10.4172/2157-7420.S11-014

Page 4 of 8

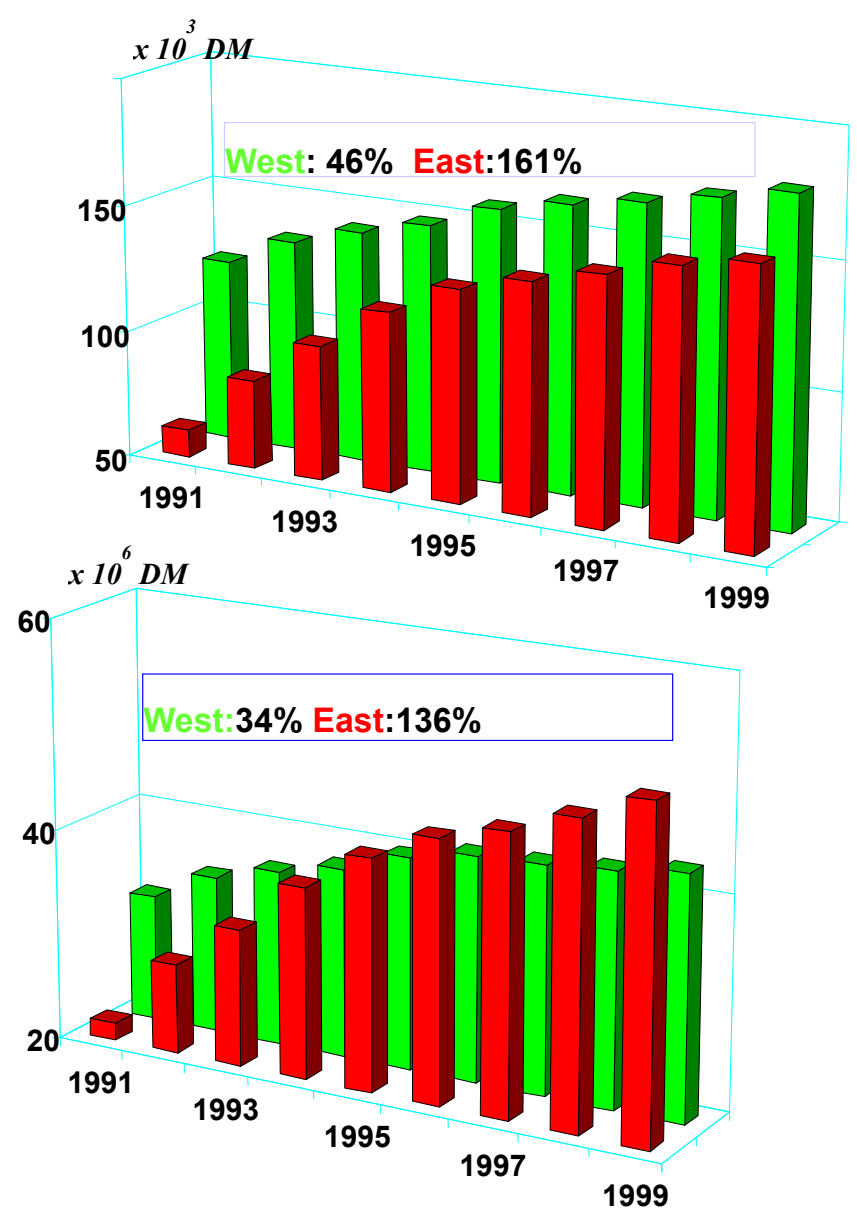

Figure 2: Adjusted costs per year and its increase after the reunification within East- and West Germany between 1991-99 with respect to hospital costs (top) and costs per patient (bottom).

home deliveries continued. At this point it is important to note that neither in the Netherlands nor in other countries had prospective randomized trial been performed to compare home versus hospital deliveries, nor had women been asked about their own opinion in this regard. Such trials are still lacking, but randomized trials may be considered ethically problematic nowadays, since in most countries outcome data of home births are significantly worse [12]. It should not be forgotten that some data might be biased since home births took or still take place in the absence of a structured setting with too motivated patients and caregivers, possibly ignoring risk factors.

In the next 2-3 decades the Dutch approach seemed right, since perinatal mortality remained one of the lowest in the world, whereas instrumental vaginal deliveries and Caesarean sections (CS) remained much lower than in neighboring countries [13]. Dutch studies showed that obstetricians who attended low-risk deliveries were more liberal in the use of oxytocic drugs, instrumental deliveries and episiotomies than both general practitioners and midwives [14]. In the early 1990s, it was shown that midwives attending low-risk deliveries in the hospital encountered more complications than they did in home deliveries [15]. These figures supported the Dutch view that hospital delivery may result in an increase of unnecessary obstetrical interventions. In the 1980s observational studies from other countries indicated the safety of home deliveries in a well-organized and supervised setting [16,17].

\begin{tabular}{|l|c|c|}
\hline German System Dutch System & German & Dutch \\
\hline Possibility to choose the place of delivery & + & - \\
\hline without financial pressure & + & - \\
\hline On-site cooperation between midwives and obstetricians & + & - \\
\hline Number of gynecologists according to OECD & + & - \\
\hline Democratically established national guidelines & - & + \\
\hline Continuity of ambulatory/clinical care in high risk pregnancies & - & + \\
\hline Standardized data scoring system for pregnant women & + & - \\
\hline "Passport for Mothers") & & \\
\hline $24 / 7$ in-hospital presence of obstetricians & + & - \\
\hline Accreditation/audit system of training based on EBCOG & - & + \\
\hline National obstetric research network & - & + \\
\hline Structured first trimester screening privately paid since 2007 & + & + \\
\hline Structured 20 weeks scan since 1982 since 2007 & + & + \\
\hline Confidential inquiries (maternal mortality) & - & + \\
\hline Perinatal Audits since 2011 & - & + \\
\hline
\end{tabular}

Table 2: Overall strengths $(+)$ and weaknesses (-) of the German and Dutch obstetrical care systems.

The Dutch system of obstetric care is based on the assumption that pregnancy and delivery are physiological events and should therefore preferably be attended by midwives, who are independent medical practitioners and GPs, to prevent unnecessary interventions, whereby continuous risk assessment is performed. Women are referred to the caregiver according to their risk category: patients who are considered low-risk are cared for by the midwife or GP, whereas those in the highrisk group are seen by the obstetrician in a hospital setting. Patient selection is first made in early pregnancy and continues with the assigned provider throughout pregnancy, delivery and puerperium. In case of recognized complications during pregnancy, an obstetrician is consulted and further care is then provided in the hospital if considered necessary. A fixed list of medical and obstetric complications is used to indicate whether referral to a gynecologist is necessary. Adequate communication and respect between these caregivers are of greater importance, since regulations will never cover all possible clinical circumstances. The Dutch system occurred more or less by chance, by the strong opinion of a few key persons and its initial success resulted in a strong backing of the system by midwives and subsequently by politicians and health care organizations. Also obstetricians were in favor of the system and a conservative approach towards pregnancy and delivery interventions became their Dutch trademark.

Recent critics on the Dutch system of perinatal care: In the second half of the first decade of this millennium the Dutch obstetric system became under pressure mainly after the publication of the results of the first and second PERISTAT data on perinatal mortality in European countries, with the Netherlands ranking more or less on the bottom of the list [18]. Initially many health care professionals ignored these data pointing towards the high maternal age; high incidence of multiple pregnancies and of immigrant populations in the Netherlands, but those arguments did not explain differences with other countries. One plausible reason for part of this low ranking was the low incidence of pregnancy terminations due to fetal malformations resulting in a higher perinatal mortality rate due to the absence of a 20 weeks scan at that time.

Pressure increased further after the publication of an opinion paper entitled 'Better Birthing ', in a Dutch medical journal in 2008 [19], when the high perinatal mortality was addressed but also the high maternal mortality. Even worse, the fact that more than $50 \%$ of so-called lowrisk nulliparous women were transferred during labor to the hospital because of failure to progress or signs of fetal asphyxia and the fact that 
perinatal mortality in hospitals was $23 \%$ higher during the night than during daytime was criticized. Analysis of the high maternal mortality rate in case of preeclampsia had revealed that substandard factors had been present in $90 \%$ of cases [20,21]. The general picture was that of first line caregivers who were too reluctant and therefore late in their referrals and obstetricians who were too expectant in their management in case of referral of these patients. Indeed, the Dutch obstetric conservatism with a general belief in a favorable outcome without too many interventions, also in case of complicated pregnancies. The same may well hold true for term stillbirths (without malformations), which were almost twice as high as in Flanders or Finland. So it seemed as if the initial successful conservative approach had become too much of a religion whereby risk factors were underestimated. Perinatal mortality in the Netherlands had been reduced from 2\% to 1\% in between 1970 and 2005 , but mortality had fallen more rapidly in other countries possibly because current technology-more effective than in the 1950s and 60 s-had been underused. The high referral rate of healthy nulliparous women during labor may well be explained by the fact that care during labor-the stronghold of midwives in the early days-had been neglected due to busy working days and to a reduction in the presence of specially trained maternity home care assistants. That left the majority of women laboring at home with no real support, with a midwife visiting her only once every 2 to 4 hours. Studies with so-called Doula's have shown the importance of the continuous presence of a companion or caregiver, on the outcome of the delivery [22] . Women experiences the satisfaction of a delivery at home as high, but considers the burden of a referral during labor even higher and some had psychological problems even some years later [23].

So the lessons learned are that in the Netherlands there is a loss of the important aspect of care (not only at home but also in hospitals) and a persistence of a too conservative approach towards risk factors during pregnancy and delivery.

A Steering Committee installed by the Minister of Health Care acknowledged the high perinatal mortality and emphasized the importance of a more pro-active approach towards the care during pregnancy and delivery, a closer collaboration between the different (independent) health care professionals, the institutionalization of a case manager who has the overall responsibility for the patient, better care for immigrants, continuous care during labor and delivery and a better $24 / 7$ availability of care givers in the hospitals [24]. The issue of home deliveries did not play an important role in the report of the steering committee, but this changed after the publication of prospective cohort study in the Netherlands on perinatal mortality and severe morbidity in low and high risk term deliveries in 2010 [25]. The authors concluded that infants of pregnant women at low risk whose labor started in primary care under the supervision of a midwife had a higher risk of delivery related perinatal death and the same risk of admission to a neonatal intensive care unit, compared with infants of pregnant women at high risk whose labor started in secondary care under the supervision of an obstetrician. These unexpected findings underline the importance of a further evaluation of the obstetric care system, despite some limitations of this study. This currently takes place in a committee involving all parties.

In the meantime, perinatal mortality, especially around term, is falling rapidly, most likely due to the fact that care givers have acknowledged the partly suboptimal and conservative obstetrical care and have become more proactive. This has resulted in an increase in inductions of labor, but the rate of cesarean delivery has remained low (around 15\%). Home births are gradually decreasing, with about one percent per year till about 23\% in 2012 (www.nationaalkompas.nl/zorg/ sectoroverstijgend/verloskundige-zorg/verschillen-internatio-naal). The system is adapting to this change by institutionalizing birthing centers led by midwives and located in/next to hospitals, thereby avoiding transport from home to hospital in case of need of referral.

One of the problems mainly in the Netherlands is that women still have to pay when they wish to deliver within a hospital with the support of an obstetrician and perinatal surveillance including ultrasound or continuous fetal heart rate monitoring. There is a medical and political challenge for transparent informed consent and for daily cooperation between midwives and obstetricians, so that midwives can advise obstetricians as to how to prevent unnecessary interventions but also enabling obstetricians to supervise midwifery care before and during labor.

\section{Other characteristics of the German and Dutch obstetrical system}

Other differences of the German and Dutch obstetrical care systems have already been mentioned in the introduction. Here we briefly illustrate some aspects.

Cost effectiveness and continuity of care: More than 50\% of German gynecologists work in private ambulatory settings, whereas in the Netherlands, both outpatient and clinical obstetric care mostly take place at hospitals. According to the OECD data system the rate of gynecologists and obstetricians per 100.000 women is 37 in Germany (far above the mean OECD rate of 28) but only 15.7 in the Netherlands, e.g. one of the lowest within Europe, although the rate of deliveries/100000 is 11 in the Netherlands and only 8 in Germany (www.indexmundi. $\mathrm{com} / \mathrm{map} / ? \mathrm{v}=25 \& \mathrm{r}=\mathrm{eu} \& \mathrm{l}=\mathrm{en})$. One reason for this large discrepancy is the fact, that outpatient care for women in the Netherlands is also covered by general practitioners, midwives or gynecologists working at hospitals. In addition, the average salary of a Dutch gynecologist is highest within Europe. This is partly controlled by limiting the number of gynecologist in training and may improve the quality of training but not of patient care. Having worked in both systems for more than 15 years, it is retrospectively still hard to understand that within a Dutch perinatal center with 3000 risk deliveries, there was only one resident present within the hospital during night shifts, responsible for both obstetrics and gynecology and even without midwives caring for patients during labor. The advantages may be that the learning curve of the trainee is growing fast, but it also reflects that inadequate care mainly in case of emergencies is more easily tolerated than in Germany. Inadequate financing may withhold the 24 hours/7days presence of all important caregivers (obstetrician, anesthesiologist, and neonatologist) in the hospital. Similarly, care during the process of labor is hampered by lack of nurses and midwives within the hospital.

On the other hand, the German advantage of having more obstetricians and midwives available can develop to a disadvantage, when there is a discontinuity between clinical and ambulatory care, mainly when there are no comprehensive guidelines for both communication and medical treatment. However, all German pregnant women are equipped with a so-called "Mutterpass", a booklet in which all essential data from previous and present pregnancies are documented including laboratory tests, ultrasound results, medication and clinical data, thus somehow standardizing prenatal care (www. mutterpass.de). Meanwhile, this very useful tool already exists as an electronic device mainly used in Switzerland but most probable being the future data storing system also for German pregnancies when all gynecologists can store and read the data electronically. 
Training: The European Board and College of the Obstetrics and Gynaecology (EBCOG) was founded in 1996 with the objective to improve the health of women and their babies by promoting the highest possible standards of care in European countries. EBCOG works closely with the four sub-specialist pillars of Materno-Fetal Medicine (EAPM), Gynecological Oncology (ESGO), Reproductive Medicine (ESHRE) and Urogynecology (EUGA). EBCOG also cooperates with other specialist organizations in Europe through a Standing Committee on Training and Assessment and works closely with the European Network of Trainees in OBGYN (ENTOG) in order to support the next generation of practitioners in our field.

Over the past 15 years, one of the core activities of EBCOG has been to promote quality assurance of training in general OBGYN and the four subspecialties. This initiative has been delivered by an organized on site hospital visiting program. Visited centers for basic training in Germany were 19, in the Netherlands 2. For the subspecialty of maternofetal medicine there was no visit in either country (www.ebcog.org). The reason for this discrepancy is the long tradition of an obligatory audit and accreditation system within Dutch training hospitals even before it was established by EBCOG. In contrast, in Germany there is still no audit and accreditation system for trainees. This means that the quality of training highly depends on the individual characteristics of the training center and the head of the department within a still hierarchical system. In contrast, residents in the Netherlands have a voice in criticizing and improving their training center. Hospital visiting at regular intervals care for the realization of the essential needs contributing to professional competence. Dutch residents can use internet platforms and log books to document their progress within this important period. Although the German Board for Obstetrics and Gynecology also recommends a log book and documented supervision of the training period, this is rarely realized. A countrywide German study investigated how heads of departments and their residents scored basic criteria of residency (e.g. atmosphere, mistake management, evidence-based guidelines). The discrepancy between trainers and trainees was highest within the discipline of OBGYN, whereby the teachers thought to be unique whereas the residents scored their training to be of low quality (www.bundesaerztekammer.de). It is thus not surprising that when searching for publications about the development of good training criteria within PUBMED we could find 750 publications dealing with training of residents in OBGYN, there were 4 Dutch papers but none from Germany; most papers derived from Anglo-American countries.

More important for a team approach is the fact that in the Netherlands, both trainers and trainees are obliged to take part in regular training of how to cope with emergencies and triage based on British guidelines: Manual of Obstetric Emergency and Trauma=MOET (www.rcog.org.uk). It is hard to imagine that this would become a reality within Germany.

\section{Guidelines, malpractice and retrospective audits}

Similarly, there are large discrepancies with respect to the establishment and development of guidelines. Within the Netherlands, there is a democratic culture whereby all perinatal centers send a specialist in maternal-fetal medicine to meetings which take place twice a year and whereby obstetric topics are proactively prepared, then discussed and finally proposed to the Board of the Dutch society for OBGYN. More than 50 guidelines and 5 quality criteria related to obstetric problems and prenatal diagnosis are transparent to patients via a website (www.nvog.nl) but are also used for medical-legal affairs, which are accompanied by a specified delegate of the Dutch Board of
OBGYN advising the judges. Thus conflict of interest due to financial or professional bias is avoided. The low burden of medico-legal problems in the Netherlands may partly be due to these nationwide accepted guidelines. Structured first trimester screening and the so-called 20 weeks scan were introduced rather late in the Netherlands and that may partly explain the relatively high perinatal mortality rates.

In contrast, German guidelines are incidentally established by people who regard themselves as competent, rarely help in daily decisions and are not systematically adapted according to new evidence. Thus they may even establish old-fashioned trends (e.g. to widely use corticosteroids, even when not necessary). So-called specialists deliberately appointed either by the federal "Ärztekammer" or by the court write expertise opinions. These experts often argue on their personal experience or knowledge rather than on the basis of defined standards. The undoubtedly higher pressure of malpractice cases within Germany compared to the Netherlands is therefore a higher burden for both patients and specialists. It would be interesting to compare medical claims within Europe or even within Western countries. Prenatal ultrasound diagnosis was much earlier introduced in Germany compared to the Netherlands: Already in 1982 the section of OBGYN of the German society of ultrasound introduced a three-step concept for basic needs during pregnancy (I), a specific screening system to diagnose or exclude malformations mainly at 20 weeks (II) and competent centers for rare prenatal diseases, intrauterine therapy and highly qualified teaching (III) (www.degum.de) Anybody performing ultrasound has to be certified at regular intervals and to integrate new developments for teaching and patient care. At least three obligatory ultrasound examinations during the first, second and third trimester have to be documented in the "Mutterpass". In contrast, ultrasound in the Netherlands was only available "on indication" from 2007 onwards when (only) a second trimester scan became routine and a first trimester screening possible after informed consent. Nevertheless, also the third trimester scan may be essential for outcome of pregnancy and planning delivery and this is still not covered as a routine tool.

An advantage for postgraduate teaching and learning is the establishment of audits in case of maternal deaths (confidential inquiries) and the scientific evaluation of these sad events in the Netherlands [3,21, 26-28]. In Germany, this important topic is not professionally analyzed. The statistical evaluation depends on deliberate information of the statistical offices within the German provinces but these are incomplete. The lessons to learn from these cases are not used, which is mainly due to a fear this could provoke malpractice claims. The introduction of systematic perinatal audits in case of perinatal mortality and morbidity (which were standard already before 1990 in Eastern Germany) would be another step to develop our discipline as one of the most important within medicine, namely to improve health of our future population and feel responsible in cases of poor outcome. This has now been introduced in the Netherlands.

\section{Scientific output}

Dutch sailors and traders have a long tradition to look beyond the horizons and this also holds true for scientific developments within our faculty, whereas Germans have a more introverted way to reflect which theoretically enables them to creative work such as in philosophy, music and possibly also to create pioneer developments. Academic centers in the Netherlands do not define themselves by the number of routine treatments but mainly by the originality of good publications based on science and clinical epidemiology. Young students or residents are motivated to take part in the scientific specialties defined for each academic center or even better are motivated to take part in the national 
network for the establishment and realization of randomized trials by a national network ("Consortium") established by Ben Willem Mol in the early years of this millennium. Thus, in 2012 alone, 2495 obstetric patients could be randomized for different prospective trials (www. studies-obsgyn.nl/home/page.asp?page_id=328). The results could meanwhile be published in high-impact journals, mostly with a young resident as the first author [29-40]; at present there are 5 obstetric trials still running.

In contrast, there are very few research lines within German obstetric units and the dominance of oncology at most academic centers even makes any recognition or financial support of fetal-maternal medicine more difficult. In addition, during and after the Second World War many good scientists have left Germany to continue their career in the US thus creating a lack of intellectuality at German Universities. Ironically it now seems an advantage that East German scientists had to stay within the country. Nevertheless, the number of publications in international journals deriving from the Dutch obstetric scene is much higher compared to Germany. This all reflects that intellectual output within our specialty is neither recognized nor supported in the German setting unless performed as a private hobby.

It possibly would be great to combine the (German) creativity with the (Dutch) pragmatism and scientific methodology within future research lines as it has recently been shown in a randomized trial using pessaries for the prevention of preterm birth in twins [41] .

\section{Concluding Remarks}

The German and Dutch obstetrical care systems started from about the same origin after World War II. German obstetric care diverted into two different systems with preventive medicine dominating in the East and technology in the West. It is not true, that the Western system was superior, since the outcome was not significantly different and mothers even seemed more satisfied within the Eastern system (own unpublished data). After 1990, the system emerged leading to a tremendous increase of costs, but no increase of satisfaction because some of the good East German features of social medical care were abolished.

After 1990, also within the Netherlands things have moved. A crucial disadvantage compared with the German system still remained, namely that pregnant women with a low risk pregnancy still have to pay to be followed by a specialist during pregnancy or to deliver with modern surveillance. The question remains, whether general practitioners or midwives can early recognize, when low risk- become medium- or high-risk pregnancies either during pregnancy or during delivery. In this aspect, the German system of a closer daily cooperation between midwives and obstetricians offer more possibilities that both aspects of obstetric care-empathy and professional surveillance-are simultaneously combined.

Lessons to learn from the comparison are to adapt the number and quality of our future obstetricians. The Netherlands might have too few, Germany too many gynecologists. Dutch residents have better chances to participate in scientific research lines and thus learn how to read and interpret the present and future literature. There is a large need for a standardized audit and accreditation system for training within the German system and they do not even have to cross oceans but only the Dutch-German border to get experience. This also implies to the establishment of competent guidelines, standards and confidential inquiries not only for pre- and postgraduate training but also for transparency towards our patients.

Superficially it seems that there is 'more than one way to Rome'. But differences in maternal and neonatal outcome and the quality of our future specialists are a challenge. Therefore it is necessary to analyze which structures are causal for good outcome and satisfaction of patients and professionals and which are not. Lessons to be learned are that modern technology and an active approach seem necessary to bring an already low perinatal mortality rate further down. However, care and a human approach should not be forgotten and preventive strategies, screening and education may prove to be even more important.

Industrialized countries face pressure to continuously reform their health care systems. There is an increasing awareness of patients within a global society with modern media. We have to balance universal access to a sophisticated health care on one side and the escalating costs for a high-technology medicine on the other. Within Europe, we are all enriched by our reciprocate differences in many aspects of our life. Given the differences between both countries we hopefully can learn to better argue with politicians and professional boards to change things when necessary. Most importantly, we may improve future care of the fetal and maternal patient and thereby possibly move, to neglect harmful sides, introduce useful aspects and finally speak with one language. Then we have to draw the attention of the society to the fact, that investigating financial resources of prevention at the beginning of life is as essential-if not more-than spending it in questionable efforts at the end of life when empathy of care is in fact more essential than extremely invasive procedures.

\section{References}

1. Kent A (2010) World maternal mortality rates. Rev obstet Gynecol 3: 193-194.

2. Schuitemaker N, van Roosmalen J, Dekker G, van Dongen $P$, van Geijn $H$, et al. (1998) Increased maternal mortality in The Netherlands from group A streptococcal infections. Eur J Obstet Gynecol Reprod Biol 76: 61-64.

3. Schutte JM, Steegers EA, Schuitemaker NW, Santema JG, de Boer K, et al. (2010) Rise in maternal mortality in the Netherlands. BJOG 117: 399-406.

4. de Jonge A, Baron R, Westerneng M, Twisk J, Hutton EK (2013) Perinatal mortality rate in the Netherlands compared to other European countries: A secondary analysis of Euro-PERISTAT data. Midwifery.

5. Mohangoo AD, Buitendijk SE, Hukkelhoven CW, Ravelli AC, Rijninks-van Drie GC (2008) Higher perinatal mortality in The Netherlands than in other European countries: the Peristat-II study. Ned Tijdschr Geneeskd 152: 2718-2727.

6. Hannah Blencowe, Simon Cousens, Mikkel Z Oestergaard, Doris Chou, AnnBeth Moller, et al. (2012) National, regional, and worldwide estimates of preterm birth rates in the year 2010 with time trends since 1990 for selected countries: a systematic analysis and implications. Lancet 379: 2162-2172.

7. Arabin B, Raum E, Mohnhaupt A, Schwartz FW (1999)Two types of health care systems and their influence on the introduction of perinatal care: an epidemiological twin model in Berlin from 1950 to 1990. Matern Child Health J 3: 81-91.

8. Visser GH (2012) Obstetric care in the Netherlands: relic or example? J Obstet Gynaecol Can 34: 971-975

9. Saling E, Arabin B (1988) Historic landmarks of perinatal medicine in obstetrics J Perinat Med 16: 5-21

10. Schieber GJ, Poullier JP, Greenwald LM (1993) Health spending, delivery, and outcomes in OECD countries. Health Aff (Millwood) 12: 120-129.

11. (2012) Geburten in Deutschland. Statistisches Bundesamt.

12. Grunebaum A, McCullough LB, Sapra KJ, Brent RL, Levene M, et al. (2013) Apgar Score of Zero at Five Minutes and Neonatal Seizures or Serious Neurologic Dysfunction in Relation to Birth Setting. American journal of obstetrics and gynecology.

13. Scherjon S (1986) A comparison between the organization of obstetrics in Denmark and The Netherlands. Br J Obstet Gynaecol 93: 684-689.

14. SE Berghs GAH (1988) De normale zwangerschap, bevallingen beleid. PhD thesis on normal pregnancy and delivery. University Press Nijmegen Nijmegen. 
Citation: Arabin B, Visser GHA (2013) Comparison of Obstetric Care in Germany and in the Netherlands. J Health Med Informat S11: 014. doi:10.4172/2157-7420.S11-014

15. TA Wiegers, JNC Keirse, J van der Zee, GAH Berghs (1996) Outcome of planned home and planned hospital births in low risk pregnancies: prospective study in midwifery practices in The Netherlands. BMJ 313: 1309-1313.

16. Shearer JM (1985) Five year prospective survey of risk of booking for a home birth in Essex. Br Med J (Clin Res Ed) 291: 1478-1480.

17. Woodcock HC, Read AW, Bower C, Stanley FJ, Moore DJ (1994) A matched cohort study of planned home and hospital births in Western Australia 19811987. Midwifery 10: 125-135.

18. Zeitlin J, Wildman K, Bréart G, Alexander S, Barros H (2003) PERISTAT: indicators for monitoring and evaluating perinatal health in Europe. Eur J Public Health 13: 29-37

19. Visser GHA, Steegers EAP (2008) Beter baren [Better deliveries]. MedischContact 63: 96-99.

20. Steegers EA (2005) Plasma volume expansion and delaying delivery in preeclampsia. BJOG 112: 1337-1338.

21. Schutte JM, Schuitemaker NW, van Roosmalen J, Steegers EA (2008) Substandard care in maternal mortality due to hypertensive disease in pregnancy in the Netherlands. BJOG 115: 732-736.

22. Scott KD, Berkowitz G, Klaus M (1999) A comparison of intermittent and continuous support during labor: a meta-analysis. Am J Obstet Gynecol 180: 1054-1059.

23. Rijnders $M$, Baston $H$, Schönbeck $Y$, van der Pal K, Prins $M$, et al. (2008) Perinatal factors related to negative or positive recall of birth experience in women 3 years postpartum in the Netherlands. Birth 35: 107-116.

24. S. Z. e. G. S. C. on and P. D. U. (2009) Veilige zorg rond zwangerschap en geboorte (Safe care for pregnancy and birth). Utrecht 1-84.

25. Evers AC, Brouwers HA, Hukkelhoven CW, Nikkels PG, Boon J, et al. (2010) Perinatal mortality and severe morbidity in low and high risk term pregnancies in the Netherlands: prospective cohort study. BMJ 341: 5639.

26. la Chapelle CF, Schutte JM, Schuitemaker NW, Steegers EA, van Roosmalen $\mathrm{J}$, et al. (2012) Maternal mortality attributable to vascular dissection and rupture in the Netherlands: a nationwide confidential enquiry. BJOG 119: 86-93.

27. Kramer HM, Schutte JM, Zwart JJ, Schuitemaker NW, Steegers EA (2009) Maternal mortality and severe morbidity from sepsis in the Netherlands. Acta Obstet Gynecol Scand 88: 647-653.

28. Schuitemaker NW (1999) Maternal mortality in Europe; present and future. Eur J Obstet Gynecol Reprod Biol 86: 129-130.

29. van der Tuuk K, Koopmans CM, Groen H, Mol BW, van Pampus MG, et al (2011) Impact of the HYPITAT trial on doctors' behaviour and prevalence of eclampsia in the Netherlands. BJOG 118: 1658-1660.
30. Langenveld J, Broekhuijsen K, van Baaren GJ, van Pampus MG, van Kaam $\mathrm{AH}$, et al. (2007) Induction of labour versus expectant monitoring in women with pregnancy induced hypertension or mild preeclampsia at term: the HYPITAT trial. BMC Pregnancy Childbirth 7: 14

31. Boers KE, van Wyk L, van der Post JA, Kwee A, van Pampus MG, et al. (2012) Neonatal morbidity after induction vs expectant monitoring in intrauterine growth restriction at term: a subanalysis of the DIGITAT RCT. Am J Obstet Gynecol 206: 341-347.

32. Boers KE, Vijgen SM, Bijlenga D, van der Post JA, Bekedam DJ, et al. (2010) Induction versus expectant monitoring for intrauterine growth restriction at term: randomised equivalence trial (DIGITAT). BMJ 341: 7087.

33. Roos C, Spaanderman ME, Schuit E, Bloemenkamp KW, Bolte AC, et al. (2013) Effect of maintenance tocolysis with nifedipine in threatened preterm labor on perinatal outcomes: a randomized controlled trial. JAMA 309: 41-47.

34. van Mello NM, Mol F, Verhoeve HR, van Wely M, Adriaanse AH, et al. (2013) Methotrexate or expectant management in women with an ectopic pregnancy or pregnancy of unknown location and low serum hCG concentrations? A randomized comparison. Hum Reprod 28: 60-67.

35. de Graaf IM, Oude Rengerink K, Wiersma IC, Donker ME, Mol BW, et al. (2012) Techniques for wound closure at caesarean section: a randomized clinical trial. Eur J Obstet Gynecol Reprod Biol 165: 47-52.

36. David P van der Ham, Jan G Nijhuis, Ben Willem J Mol, Johannes J van Beek, Brent C Opmeer, et al. (2012) Induction of labor versus expectant management in women with preterm prelabor rupture of membranes between 34 and 37 weeks: a randomized controlled trial. PLoS medicine 9: e1001208.

37. Schuit E, Stock S, Groenwold RH, Maurel K, Combs CA, et al. (2012) Progestogens to prevent preterm birth in twin pregnancies: an individua participant data meta-analysis of randomized trials. BMC Pregnancy Childbirth 12: 13.

38. Lim AC, Schuit E, Bloemenkamp K, Bernardus RE, Duvekot JJ, et al. (2011) 17 alpha-hydroxyprogesterone caproate for the prevention of adverse neonatal outcome in multiple pregnancies: a randomized controlled trial. Obstet Gynecol 118: 513-520.

39. Westerhuis ME, Visser GH, Moons KG, van Beek E, Benders MJ, et al. (2011) Cardiotocography plus ST analysis of fetal electrocardiogram compared with cardiotocography only for intrapartum monitoring: a randomized controlled trial. Obstet Gynecol 117: 406-407.

40. Westerhuis ME, Visser GH, Moons KG, van Beek E, Benders MJ, et al. (2010) Cardiotocography plus ST analysis of fetal electrocardiogram compared with cardiotocography only for intrapartum monitoring: a randomized controlled trial. Obstet Gynecol 115: 1173-1180.

41. Liem S, Ewoud Schuit, Joke Bais, Karin de Boer, Kitty Bloemenkamp, et al. (2013) Prevention of preterm birth in women with a multiple pregnancy using a pessary (ProTWIN study): a randomized controlled trial. Lancet 2013.
This article was originally published in a special issue, Global Progresses in the Perinatal Medicine handled by Editor(s). Dr. Kazuo Maeda, Kyushu University Medical School, Japan 